\title{
Responsiveness of the EuroQoL 5- Dimension (EQ-5D) questionnaire in patients with spondyloarthritis
}

Helen Hoi Lun Tsang ${ }^{1 \dagger}$, Carlos King Ho Wong ${ }^{2}$, Prudence Wing Hang Cheung ${ }^{3}$, Chak Sing Lau', Ho Yin Chung ${ }^{1}$ and Jason Pui Yin Cheung ${ }^{3^{*}+}$ (i)

\begin{abstract}
Background: Spondyloarthritis (SpA) has a significant impact on patients' quality of life due to functional impairments. Generic health instruments like the EuroQoL 5-dimension (EQ-5D) is important for cost-utility analysis of health care interventions and calculation of quality-adjusted life-years. It has been validated in patients with SpA. However, its responsiveness property is unclear. Hence, the aim of study is to test the responsiveness properties of the EQ-5D health measure for Chinese patients with SpA.

Methods: Prospective and consecutive recruitment of 151 Chinese patients with SpA was conducted with followup assessments 6 months later. Demographic data including smoking and drinking habits, education level, income and occupation was collected. Disease-associated data including disease duration, presence of back pain, peripheral arthritis, dactylitis, enthesitis, uveitis, psoriasis, and inflammatory bowel disease was also recorded. Questionnaires regarding disease activity and functional disability (BASDAI, BASFI, BASGI, BASMI, ASDAS), mental health (HADS) and the EQ-5D scores were recorded. Responsiveness was tested against the global rating of change scale (GRC) and changes in disease activity using BASDAI and ASDAS-CRP.
\end{abstract}

Results: A total of 113 (74.8\%) patients completed the follow-up assessments. Most patients (61.6\%) had low disease activity level with BASDAI $<4$ and $39.7 \%$ of patients had inactive disease by ASDAS-CRP. EQ-5D scores was well discriminated along with BASDAI and BASFI scores. EQ-5D scores also correlated well with HADS. The GRC was not able to discriminate adequately. No significant ceiling or floor effect was observed.

Conclusions: EQ-5D demonstrates satisfactory responsiveness property for assessment of changes in SpA disease activity.

Level of evidence: ॥

Keywords: Spondyloarthritis, EQ-5D, SpA, HRQoL

\footnotetext{
* Correspondence: cheungjp@hku.hk

${ }^{\dagger}$ Helen Hoi Lun Tsang and Jason Pui Yin Cheung contributed equally to this work.

${ }^{3}$ Department of Orthopaedics and Traumatology, The University of Hong

Kong, Professorial Block, 5th Floor, 102 Pokfulam Road, Pokfulam, Hong Kong

SAR, China

Full list of author information is available at the end of the article
}

(C) The Author(s). 2021 Open Access This article is licensed under a Creative Commons Attribution 4.0 International License, which permits use, sharing, adaptation, distribution and reproduction in any medium or format, as long as you give appropriate credit to the original author(s) and the source, provide a link to the Creative Commons licence, and indicate if changes were made. The images or other third party material in this article are included in the article's Creative Commons licence, unless indicated otherwise in a credit line to the material. If material is not included in the article's Creative Commons licence and your intended use is not permitted by statutory regulation or exceeds the permitted use, you will need to obtain permission directly from the copyright holder. To view a copy of this licence, visit http://creativecommons.org/licenses/by/4.0/. The Creative Commons Public Domain Dedication waiver (http://creativecommons.org/publicdomain/zero/1.0/) applies to the data made available in this article, unless otherwise stated in a credit line to the data. 


\section{Background}

Assessing changes in clinical status for patients with chronic illness is important. This provides clinicians and caretakers a method to gauge treatment response and deterioration in condition. The patients' health status may not always be apparent to clinicians. Self-reported health-related quality of life (HRQoL) scores provide a subjective assessment of patient health. One chronic illness that is particularly relevant is spondyloarthritis (SpA). SpA encompasses a group of interrelated rheumatic conditions including ankylosing spondylitis (AS), psoriatic arthritis (PsA), spondyloarthritis associated with inflammatory bowel disease (IBD) and reactive arthritis. AS, regarded as the prototype of SpA, has been shown to be associated with greater work disability (WD) compared to the general population, with WD rates varying from $3-50 \%$ in western countries [1-3]. Patients with AS are 3.1 times more likely to have withdrawal from work than expected in the general population and they are also more likely to experience a lower quality of life (QoL) [4, 5]. This in turn will result in loss of work productivity and increased socioeconomic burden. Studies have also shown that patients with axial SpA report a lower HRQoL than do healthy controls and this reduction in HRQoL is associated with fatigue, pain, increased disease activity, and decreased daily activity and exercise [6-8]. In addition, a lower HRQoL in SpA patients is associated with adverse psychological outcomes and a higher prevalence of anxiety and depression [9].

There are mainly two different types of HRQoL instruments, namely disease-specific and generic, to assess patients of chronic diseases. For axial SpA, disease-specific tools for assessing functional disability include Bath Ankylosing Spondylitis Functional Index (BASFI), the Leeds Disability Questionnaire (LDQ) and the Dougados Functional Index (DFI). Generic instruments are more useful for assessments of the disease impact by allowing comparisons between different disease populations.

The EuroQoL 5-dimension (EQ-5D) is a generic health measure instrument developed by the EuroQoL group, which allows a quantitative expression of the individual's perception of their overall health status [10]. It serves as an important utility measure for clinical and economic appraisal, particularly in the cost-utility analysis of various health care interventions, and the calculation of quality-adjusted life-years (QALYs). It has been applied to the Chinese population previously [11] and has been shown to be useful in assessing QoL in patients with SpA [12]. However, the responsiveness of EQ-5D to changes in disease status over time in patients with SpA is unclear. Responsiveness refers to the ability of a score to capture underlying changes in a patients' health status over time. It is essential for clinicians to assess whether the treatment provided has improved the QoL in patients and whether further escalation of treatment is required. EQ-5D is also a valuable tool as it allows cross comparison with other rheumatological diseases. Hence, the aim of this study is to test the responsiveness of the EQ-5D in patients with SpA.

\section{Methods}

A total of 151 consecutive patients of Chinese ethnicity were prospectively recruited from two rheumatology specialist clinics between May to December 2017 and subsequently reassessed at a follow-up of 6 months later (November 2017 to June 2018). All recruited patients were diagnosed to have either axial SpA or peripheral SpA by rheumatologists based on the Assessment of Spondyloarthritis international Society (ASAS) criteria [13-15] and by expert opinion. All recruited patients were 18 years old or above. Patients who did not give consent for participation, non-Chinese, illiterate and unable to comprehend the instruments were excluded. Subjects who consented were interviewed for a panel of sociodemographic and disease-associated parameters, disease activity and severity factors, and HRQoL scores that highlight the functional and mental health status. Both baseline and follow-up interviews were conducted in person at the consultation clinic. At the follow-up interview, subjects were assessed by the same research personnel for a reassessment of the same study questionnaires as well as the global rating of change scale. To provide good quality of psychometric evidence, sample size of at least 100 was recommended by Terwee et al [16]. Ethics was approved by the local institutional review board. All methods were carried out in accordance with relevant guidelines and regulations.

\section{Sociodemographic and disease-associated data}

Patients' smoking and drinking habits, education level, income and occupation were recorded. Diseaseassociated data including disease duration, presence of back pain and/or peripheral arthritis, dactylitis, enthesitis, and extra-articular manifestations such as uveitis, psoriasis, and IBD were collected. Baseline treatment including the use of non-steroidal anti-inflammatory drugs (NSAIDs) or cyclooxygenase-2 (cox-2) inhibitors, disease modifying anti-rheumatic drugs (DMARDs) and biologics and any subsequent change in treatment after 6 months were documented. Physical examination was performed to determine the number of tender joint count and swollen joint count, the dactylitis and enthesitis scores. Antero-posterior radiograph of the lumbosacral spine was utilized for grading of sacroiliitis according to the modified New York criteria [17] by a rheumatologist (HYC) who was blinded to the clinical data. Radiological sacroiliitis was graded as: 0 , normal; 1 , suspicious; 2 , minimal sclerosis with 
some erosions; 3 , erosion with widening of joint space and possible partial ankyloses; 4, complete ankyloses. Bilateral sacroiliitis of grade 2 or above, or unilateral sacroiliitis of grade 3 or above was defined as AS. Patients were treated by the attending rheumatologist according to their disease activity and severity.

\section{Disease activity and severity scores}

All recruited patients filled in the Bath Ankylosing Spondylitis Disease Activity Index (BASDAI) [18] and BASFI [19] to determine the disease activity and functional disability respectively. Spinal mobility was assessed clinically to determine the Bath Ankylosing Spondylitis Metrology Index (BASMI) score [20]. The Bath Ankylosing Spondylitis Global Index (BASGI) [21] and C-reactive protein (CRP) were measured for calculation of the Ankylosing Spondylitis Disease Activity Score-CRP (ASDAS-CRP) [22], which is a composite disease activity measure of SpA. Human leucocyte antigen (HLA) B27 status was also checked as a poor prognostic marker. BASDAI and ASDA $\mathrm{S}$ are more often used for patients with axial disease. However, both tools have demonstrated good discriminatory ability in patients with peripheral SpA as well [23].

\section{Functional and mental health status}

The SF-36 [24-26] was used for assessment of mental and physical health and as a comparable generic questionnaire marker of EQ-5D changes. Hospital Anxiety and Depression Scale (HADS) [27] is a fourteen-item scale with seven items each for anxiety and depression subscales. It has been validated in Chinese axial SpA patients and is found to useful in screening for depressive and anxiety disorders in SpA [28].

The main study parameter was the EQ-5D which is a standardized measure of health status developed by the EuroQoL group that allows a generic assessment of health status for clinical and economic appraisal [10]. It has been useful in assessing the HRQoL in patients with musculoskeletal problems [29-33]. It consists of a 2page questionnaire, the EQ-5D descriptive system and the EQ visual analogue scale (EQ VAS). The descriptive system is comprised of 5 domains, including mobility, self-care, usual activities, pain/discomfort and anxiety/ depression. There are 2 versions of EQ-5D, namely the EQ-5D-3 level (EQ-5D-3L) and the EQ-5D-5 level (EQ$5 \mathrm{D}-5 \mathrm{~L}$ ) versions. For the EQ-5D-3L, each domain will be scored by 3 levels (no problem, some problem and extreme problem). We utilized the EQ-5D-5L version for this study and each domain of this parameter was scored by 5 levels with 1 representing no problem and 5 representing extreme problem. Previous studies published by EuroQoL group have shown that the 5 level version could significantly increase reliability and sensitivity while maintaining the feasibility of the test and it could potentially reduce ceiling effects [10]. The scores of the 5 domains are combined into a 5-digit number which is converted into a single index value. The EQVAS allows patients to self-report their own perceived quality of life from a scale of 0 (worst) to 100 (best). We applied Chinese-specific EQ-5D-5L value set ranging from -0.391 for the worst health status ('55555') to 1 for the best health status ('11111') to estimate EQ score [34].

\section{Generic and Clinical Anchors}

It was necessary to include an external anchor to act as a reference for indicating patient improvement or deterioration. To test the responsiveness of EQ-5D, this anchor represented the patient-reported assessment of health change over time and thus indicate whom change in health occurred [35]. The global rating of change (GRC) scale is a single-item outcome measure for independent scoring of self-perceived improvement in a patient retrospectively and has been used in musculoskeletal research [36]. All subjects answered the question "Compared to the previous visit, how would you rate your overall health now?" [36]. The response scale was a seven-point Likert scale ranging from -3 to 3 corresponding to the 'much worse' to the 'much better' options with 0 for 'no change'. Three groups were defined using this scale: 'worse' (-3 to -1 ), 'unchanged' (0) and 'improved' (1 to 3 ) and such regrouping or categorization was applied in previous studies to evaluate responsiveness [30, 37].

The GRC was a generic anchor used to test the overall patient improvement or deterioration. Clinical anchors were also applied namely BASDAI and ASDAS-CRP to assess the changes in disease activity. These differences were more representative of actual improvement or deterioration in the disease as compared to the GRC scale which may be subjected to mental and psychological influences.

\section{Statistical analysis}

Overall descriptive characteristics were reported with mean \pm standard deviation (SD). Any differences between baseline and follow-up were compared using independent t-test and Chi-squared test where appropriate. The responsiveness of the EQ-5D was assessed using the effect size statistics. Differences between baseline and follow-up of the utility score was evaluated by standardized effect size (SES) and standardized response mean (SRM) separately for GRC, BASDAI, BASFI and ASDA $\mathrm{S}$-CRP. We have adopted the minimum clinically important improvement (MCII) of 1.1 for BASDAI and 0.6 for BASFI [38]. Change in the MCII of BASDAI and BASFI will be correlated with change in EQ-5D. As for ASDAS-CRP, it is categorized as inactive disease $(<1.3)$, moderate disease activity $(1.3-<2.1)$, high disease activity $(2.1-<3.5)$, and very high disease activity $(>3.5)$. A change 
of 1.1 is considered as clinically significant change [39]. The SES and SRM results were interpreted as trivial for values $<0.2$, small for values $\geq 0.2$ to $<0.5$, moderate for values $\geq 0.5$ to $<0.8$, and large for values $\geq 0.8$ [40]. Differences in mean change at follow-up by disease activity assessment with BASDAI and BASFI, and GRC, were performed along with area under the curve analysis (AUC).

Spearman's correlation was performed to assess the relationship between changes in EQ-5D scores with erythrocyte sedimentation rate (ESR), C-reactive protein (CRP), ASDAS-CRP, ASDAS-ESR, BASDAI, BASFI, SF36 , and HADS. Spearman's correlation was used because the data was not normally distributed as reviewed by the Shapiro-Wilk normality test. The correlation coefficient is considered weak at 0.3 , moderate at 0.5 and strong at 0.7. All statistical analyses were conducted using STATA version 13.0. A p-value of $<0.05$ was considered as statistically significant and $95 \%$ confidence intervals (CIs) were listed as appropriate.

\section{Results}

From a total of 151 Chinese patients with SpA recruited consecutively at baseline, $113(74.8 \%)$ completed the follow-up assessments. The baseline demographics are listed in Table 1 . The mean age of subjects who completed all assessments was $44.7 \pm 13.0$ years, and $66.4 \%$ of them were male patients. Most patients (61.6\%) had low disease activity with BASDAI of $<4$ and $39.7 \%$ of patients had inactive disease by ASDAS-CRP. For the baseline treatment, $75.5 \%$ of the patients were on NSAIDs or cox-2 inhibitors, $31.8 \%$ were on DMARDs (including sulphasalazine, methotrexate and/or leflunomide) and $25.8 \%$ were on biologics (including tumour necrosis factor inhibitors, secukinumab or ustekinumab).

The mean change of EQ-5D and EQ-VAS scores by disease activity and GRC are shown in Tables 2 and 3. Improved and worsened EQ-5D scores discriminated well with change in disease activity level measured by BASDAI (improved: $p=0.012$, $\mathrm{SES}=0.84$, $\mathrm{SRM}=0.87, \mathrm{RS}=$ 1.05 ; worsened: $p=0.004, \mathrm{SES}=-0.70, \mathrm{SRM}=1.00, \mathrm{RS}=-$ 0.74). Using the MCII, the EQ-5D scores discriminated well with BASDAI $(p=0.001, \mathrm{SES}=1.07, \mathrm{SRM}=1.19, \mathrm{RS}=$ 1.03) and with BASFI $(p=0.001, \mathrm{SES}=0.79, \mathrm{SRM}=1.12$, $\mathrm{RS}=0.73)$. Post-hoc power analysis showed that sample sizes of 13 in a group of worsened disease activity measured by BASDAI achieved $96 \%$ to detect a difference of -0.08 with an estimated SD of 0.08 and a significance 0.05 using one-sided one sample t-test, and sample size of 12 in an improved group achieved $86 \%$ to detect a difference of 0.11 assuming an estimated SD of 0.13 using one-sided one sample t-test. Up to 88 patients did not have a change in disease activity level based on BASDAI. For BASDAI and BASFI MCII, the mean difference detected was 0.16 and 0.15 respectively. The effect size (1.36 and 1.29) and AUC (0.85 and 0.83) were acceptable. There were no patients listed as clinically improved with the ASDAS-CRP. No significant findings were observed for the GRC. When comparing the EQ5D scores at baseline and follow-up, no significant ceiling or floor effects were observed (Table 4). Comparing the differences in EQ-5D-5L scores from baseline to follow-up (Fig. 1), there was overall improvement in various domains: mobility (31.4\% with one level reduction), usual activities (22.9\% with one level reduction), pain/discomfort (22.9\% with one level reduction), depression/anxiety $(17.1 \%$ with one level reduction) and self-care (17.1\% with one level reduction). Change in EQ-5D score correlates with changes in the SF36 domains of physical function $(r=-0.202 ; p=0.036)$, role limitation due to physical function $(r=-0.205 ; p=0.033)$ and role limitation due to emotional problems ( $r=-$ $0.247 ; p=0.009)$. Similarly, change in EQ-5D scores significantly correlated with both anxiety and depression domains of HADS. There was no correlation between the change in EQ5D scores and change in treatment at 6 months but the addition of NSAIDs/cox-2 inhibitor was significantly associated with improvement in EQVAS score (Table 5).

\section{Discussion}

SpA is a chronic debilitating disease that significantly reduces a patient's QoL. The disease cannot be eradicated and thus patients require prolonged treatment to control the disease process and reduce symptomatology. Constant monitoring is necessary as symptoms and disease activity may fluctuate and warrant prompt adjustment of medications. This carries a heavy toll on patients' physical and mental wellness as they are faced with changing treatment outcomes, for better or worse, and facing new concerns and complications. With the high cost for various disease-modifying drugs, it is important for the patients and medical practitioners to design the most cost-effective strategies. Determining QALYs aid in this understanding of disease burden on the healthcare system, which will in turn drive various institutional policies based on cost-utility analyses. The EQ-5D has been shown to be an effective utility score for SpA. We have found the EQ-5D to discriminate improved and worsened disease activity levels well in patients with SpA.

The EQ-5D instrument is a good measure of disease activity change as shown by its strong association with clinically significant changes in BASDAI and BASFI scores shown by the SES and SRM. The SES was near 0 in the unchanged group which verifies its accuracy in detecting change. The SES of EQ-5D for the improved group was 0.84 and for the worsened group was -0.70 . These results were similar to that of other chronic 
Table 1 Demographic and clinical characteristics of patients

\begin{tabular}{|c|c|c|c|c|c|}
\hline & & $\begin{array}{l}\text { Baseline } \\
(N=151)\end{array}$ & $\begin{array}{l}\text { Follow-up Completion } \\
(N=113)\end{array}$ & $\begin{array}{l}\text { Follow-up Incompletion } \\
(N=38)\end{array}$ & $P$-value \\
\hline \multicolumn{6}{|l|}{ Demographic, \% (n) } \\
\hline Age, mean $\pm S D$ & & $45.5 \pm 13.0$ & $44.7 \pm 13.0$ & $47.6 \pm 12.7$ & 0.234 \\
\hline \multirow[t]{3}{*}{ Gender } & & & & & 0.145 \\
\hline & Female & $30.5 \%(46)$ & $33.6 \%(38)$ & $21.1 \%(8)$ & \\
\hline & Male & $69.5 \%(105)$ & $66.4 \%(75)$ & $78.9 \%(30)$ & \\
\hline \multirow[t]{4}{*}{ Smoking } & & & & & $0.011^{*}$ \\
\hline & Non-smoker & $81.5 \%$ (123) & $86.7 \%(98)$ & $65.8 \%(25)$ & \\
\hline & Smoker & $9.9 \%(15)$ & $6.2 \%(7)$ & $21.1 \%(8)$ & \\
\hline & Ex-smoker & $8.6 \%(13)$ & $7.1 \%(8)$ & $13.2 \%(5)$ & \\
\hline \multirow[t]{5}{*}{ Drinking } & & & & & 0.732 \\
\hline & Non-drinker & $29.3 \%(44)$ & $30.4 \%(34)$ & $26.3 \%(10)$ & \\
\hline & Ex-drinker & $11.3 \%(17)$ & $9.8 \%(11)$ & $15.8 \%(6)$ & \\
\hline & Social drinker & $55.3 \%(83)$ & $55.4 \%(62)$ & $55.3 \%(21)$ & \\
\hline & Current drinker & $4.0 \%(6)$ & $4.5 \%(5)$ & $2.6 \%(1)$ & \\
\hline \multirow[t]{4}{*}{ Education level } & & & & & $0.009^{*}$ \\
\hline & Primary & $8.0 \%(12)$ & $9.8 \%(11)$ & $2.6 \%(1)$ & \\
\hline & Secondary & $47.3 \%(71)$ & $40.2 \%(45)$ & $68.4 \%(26)$ & \\
\hline & Tertiary or above & $44.7 \%(67)$ & $50.0 \%(56)$ & $29.0 \%(11)$ & \\
\hline \multirow[t]{5}{*}{ Family income level } & & & & & 0.550 \\
\hline & $<H K \$ 10000$ & $18.0 \%(27)$ & $17.9 \%(20)$ & $18.4 \%(7)$ & \\
\hline & HK\$10000-30000 & $43.3 \%(65)$ & $41.1 \%(46)$ & $50.0 \%(19)$ & \\
\hline & HK\$30000-60000 & $20.7 \%(31)$ & $20.5 \%(23)$ & $21.1 \%(8)$ & \\
\hline & $>H K \$ 60000$ & $18.0 \%(27)$ & $20.5 \%(23)$ & $10.5 \%(4)$ & \\
\hline \multirow[t]{6}{*}{ Occupation } & & & & & 0.905 \\
\hline & Student & $7.3 \%(11)$ & $8.0 \%(9)$ & $5.3 \%(2)$ & \\
\hline & Housewife & $5.3 \%(8)$ & $4.4 \%(5)$ & $7.9 \%(3)$ & \\
\hline & Work & $72.9 \%(110)$ & $72.6 \%(82)$ & $73.7 \%$ (28) & \\
\hline & Unemployed & $3.3 \%(5)$ & $3.5 \%(4)$ & $2.6 \%(1)$ & \\
\hline & Retired & $11.3 \%(17)$ & $11.5 \%(13)$ & $10.5 \%(4)$ & \\
\hline \multicolumn{6}{|l|}{ Clinical, \% (n) } \\
\hline \multirow[t]{3}{*}{ Positive HLA-B27 } & & & & & 0.267 \\
\hline & No & $18.7 \%(26)$ & $20.8 \%(22)$ & $12.1 \%(4)$ & \\
\hline & Yes & $81.3 \%(113)$ & $79.2 \%(84)$ & $87.9 \%(29)$ & \\
\hline \multirow[t]{3}{*}{ BASDAI } & & & & & 0.588 \\
\hline & Low disease activity $(<4)$ & $61.6 \%(93)$ & $62.8 \%(71)$ & $57.9 \%(22)$ & \\
\hline & High disease activity $(>=4)$ & $38.4 \%(58)$ & $37.2 \%(42)$ & $42.1 \%(16)$ & \\
\hline \multirow[t]{5}{*}{ ASDAS-CRP } & & & & & $<0.001^{*}$ \\
\hline & Inactive disease $(<1.3)$ & $39.7 \%(60)$ & $47.8 \%(54)$ & $15.8 \%(6)$ & \\
\hline & Moderate disease activity (1.3-2.1) & $30.5 \%(46)$ & $30.1 \%(34)$ & $31.6 \%(12)$ & \\
\hline & High disease activity (2.1-3.5) & $26.5 \%(40)$ & $21.2 \%(24)$ & $42.1 \%(16)$ & \\
\hline & Very high disease activity $(>3.5)$ & $3.3 \%(5)$ & $0.9 \%(1)$ & $10.5 \%(4)$ & \\
\hline \multirow[t]{3}{*}{ Family History } & & & & & 0.655 \\
\hline & No & $71.8 \%(107)$ & $71.2 \%(79)$ & $73.7 \%(28)$ & \\
\hline & Yes & $26.8 \%(40)$ & $27.9 \%(31)$ & $23.7 \%(9)$ & \\
\hline
\end{tabular}


Table 1 Demographic and clinical characteristics of patients (Continued)

\begin{tabular}{|c|c|c|c|c|c|}
\hline & & $\begin{array}{l}\text { Baseline } \\
(N=151)\end{array}$ & $\begin{array}{l}\text { Follow-up Completion } \\
(N=113)\end{array}$ & $\begin{array}{l}\text { Follow-up Incompletion } \\
(N=38)\end{array}$ & $P$-value \\
\hline \multirow[t]{3}{*}{ Axial spondyloarthritis } & & & & & 0.078 \\
\hline & No & $17.2 \%(26)$ & $20.4 \%(23)$ & $7.9 \%(3)$ & \\
\hline & Yes & $82.8 \%(125)$ & $79.6 \%(90)$ & $92.1 \%(35)$ & \\
\hline \multirow[t]{3}{*}{ Peripheral spondyloarthritis } & & & & & $0.030^{*}$ \\
\hline & No & $83.4 \%(126)$ & $79.6 \%(90)$ & $94.7 \%(36)$ & \\
\hline & Yes & $16.6 \%(25)$ & $20.4 \%(23)$ & $5.3 \%(2)$ & \\
\hline \multirow[t]{3}{*}{ Peripheral arthritis } & & & & & 0.093 \\
\hline & No & $62.3 \%(94)$ & $58.4 \%(66)$ & $73.7 \%(28)$ & \\
\hline & Yes & $37.7 \%(57)$ & $41.6 \%(47)$ & $26.3 \%(10)$ & \\
\hline \multirow[t]{3}{*}{ Dactylitis } & & & & & 0.787 \\
\hline & No & $96.7 \%$ (146) & $96.5 \%(109)$ & $97.4 \%(37)$ & \\
\hline & Yes & $3.3 \%(5)$ & $3.5 \%(4)$ & $2.6 \%(1)$ & \\
\hline \multirow[t]{3}{*}{ Uveitis } & & & & & 0.872 \\
\hline & No & $64.2 \%(97)$ & $64.6 \%(73)$ & $63.2 \%(24)$ & \\
\hline & Yes & $35.8 \%(54)$ & $35.4 \%(40)$ & $36.8 \%(14)$ & \\
\hline \multicolumn{6}{|l|}{ Psoriasis } \\
\hline & No & $87.4 \%$ (132) & $85.0 \%(96)$ & $94.7 \%(36)$ & \\
\hline & Yes & $12.6 \%(19)$ & $15.0 \%(17)$ & $5.3 \%(2)$ & \\
\hline \multirow[t]{3}{*}{ Inflammatory Bowel Disease } & & & & & 0.994 \\
\hline & No & $97.4 \%(147)$ & $97.3 \%(110)$ & $97.4 \%(37)$ & \\
\hline & Yes & $2.6 \%(4)$ & $2.7 \%(3)$ & $2.6 \%(1)$ & \\
\hline \multicolumn{6}{|l|}{ HADS } \\
\hline & Depression & & & & 0.124 \\
\hline & Normal (0-7) & $80.6 \%(112)$ & $79.8 \%(83)$ & $82.9 \%(29)$ & \\
\hline & Borderline (8-10) & $14.4 \%(20)$ & $14.4 \%(15)$ & $14.3 \%(5)$ & \\
\hline & Abnormal (11-21) & $5.0 \%(7)$ & $5.8 \%(6)$ & $2.9 \%(1)$ & \\
\hline & Anxiety & & & & 0.407 \\
\hline & Normal (0-7) & $68.4 \%(95)$ & $71.2 \%(74)$ & $60.0 \%(21)$ & \\
\hline & Borderline (8-10) & $20.9 \%(29)$ & $19.2 \%(20)$ & $25.7 \%(9)$ & \\
\hline & Abnormal (11-21) & $10.8 \%(15)$ & $9.6 \%(10)$ & $14.3 \%(5)$ & \\
\hline Backpain duration & & $16.6 \pm 12.1$ & $15.9 \pm 11.5$ & $17.4 \pm 12.7$ & 0.540 \\
\hline \multirow[t]{3}{*}{ Current back pain } & & & & & 0.285 \\
\hline & No & $22.0 \%(33)$ & $24.1 \%(27)$ & $15.8 \%(6)$ & \\
\hline & Yes & $78.0 \%(117)$ & $75.9 \%(85)$ & $84.2 \%(32)$ & \\
\hline Tender joints & & $0.36 \pm 1.23$ & $0.40 \pm 1.36$ & $0.24 \pm 0.75$ & 0.488 \\
\hline Swollen joints & & $0.21 \pm 1.12$ & $0.25 \pm 1.28$ & $0.08 \pm 0.36$ & 0.424 \\
\hline Dactylitis score & & $0.01 \pm 0.11$ & $0.01 \pm 0.09$ & $0.03 \pm 0.16$ & 0.419 \\
\hline Enthesitis score & & $0.23 \pm 0.77$ & $0.28 \pm 0.86$ & $0.08 \pm 0.36$ & 0.158 \\
\hline \multicolumn{6}{|l|}{ Baseline treatment } \\
\hline \multirow[t]{3}{*}{ NSAIDs/COX-2 Inhibitors } & & & & & 0.892 \\
\hline & No & $24.5 \%(37)$ & $24.8 \%(28)$ & $23.7 \%(9)$ & \\
\hline & Yes & $75.5 \%(114)$ & $75.2 \%(85)$ & $76.3 \%(29)$ & \\
\hline \multirow[t]{3}{*}{ DMARDs } & & & & & $0.041^{*}$ \\
\hline & No & $68.2 \%(103)$ & $63.7 \%(72)$ & $81.6 \%(31)$ & \\
\hline & Yes & $31.8 \%$ (48) & $36.3 \%(41)$ & $18.4 \%(7)$ & \\
\hline
\end{tabular}


Table 1 Demographic and clinical characteristics of patients (Continued)

\begin{tabular}{|c|c|c|c|c|c|}
\hline & & $\begin{array}{l}\text { Baseline } \\
(N=151)\end{array}$ & $\begin{array}{l}\text { Follow-up Completion } \\
(N=113)\end{array}$ & $\begin{array}{l}\text { Follow-up Incompletion } \\
(N=38)\end{array}$ & $P$-value \\
\hline \multirow[t]{3}{*}{ Biologics } & & & & & 0.102 \\
\hline & No & $74.2 \%(112)$ & $70.8 \%(80)$ & $84.2 \%(32)$ & \\
\hline & Yes & $25.8 \%(39)$ & $29.2 \%(33)$ & $15.8 \%(6)$ & \\
\hline \multicolumn{6}{|c|}{ Baseline disease activity status } \\
\hline & BASDAl & $3.45 \pm 1.91$ & $3.43 \pm 1.90$ & $3.52 \pm 1.95$ & 0.793 \\
\hline & BASFI & $2.13 \pm 1.98$ & $2.09 \pm 2.06$ & $2.28 \pm 1.75$ & 0.610 \\
\hline & BASMI & $4.05 \pm 1.63$ & $3.98 \pm 1.56$ & $4.29 \pm 1.82$ & 0.309 \\
\hline & ASDAS-ESR & $2.36 \pm 0.92$ & $2.34 \pm 0.93$ & $2.42 \pm 0.88$ & 0.655 \\
\hline & ASDAS-CRP & $1.63 \pm 0.98$ & $1.42 \pm 0.89$ & $2.26 \pm 0.98$ & $<0.001$ \\
\hline & CRP (g/dL) & $0.76 \pm 1.57$ & $0.75 \pm 1.63$ & $0.81 \pm 1.36$ & 0.846 \\
\hline & ESR (mm/hr) & $23.26 \pm 18.21$ & $23.37 \pm 19.47$ & $22.95 \pm 14.04$ & 0.902 \\
\hline \multicolumn{6}{|l|}{ SF-36 } \\
\hline & Physical functioning & $75.97 \pm 19.90$ & $75.88 \pm 19.70$ & $76.25 \pm 20.75$ & 0.923 \\
\hline & Role limitations due to physical functioning & $70.62 \pm 25.36$ & $69.38 \pm 25.53$ & $74.18 \pm 24.84$ & 0.317 \\
\hline & Bodily pain & $33.64 \pm 8.68$ & $33.34 \pm 9.01$ & $34.54 \pm 7.65$ & 0.468 \\
\hline & General health perceptions & $54.76 \pm 9.27$ & $54.09 \pm 9.40$ & $56.73 \pm 8.72$ & 0.135 \\
\hline & Vitality & $53.93 \pm 11.51$ & $53.75 \pm 10.55$ & $54.44 \pm 14.08$ & 0.751 \\
\hline & Role limitations due to emotional problems & $72.35 \pm 23.73$ & $72.50 \pm 23.77$ & $71.93 \pm 23.92$ & 0.899 \\
\hline & Social functioning & $48.92 \pm 8.92$ & $47.99 \pm 8.48$ & $51.64 \pm 9.71$ & $0.029^{*}$ \\
\hline & Mental health & $56.17 \pm 10.62$ & $56.21 \pm 10.76$ & $56.05 \pm 10.34$ & 0.938 \\
\hline & Physical component summary & $38.24 \pm 7.24$ & $37.97 \pm 7.27$ & $39.03 \pm 7.20$ & 0.696 \\
\hline & Mental component summary & $42.76 \pm 5.34$ & $42.75 \pm 5.24$ & $42.77 \pm 5.71$ & 0.988 \\
\hline \multicolumn{6}{|l|}{ HADS } \\
\hline & Anxiety & $5.91 \pm 3.60$ & $5.76 \pm 3.61$ & $6.37 \pm 3.58$ & 0.386 \\
\hline & Depression & $4.81 \pm 3.46$ & $4.71 \pm 3.56$ & $5.11 \pm 3.17$ & 0.553 \\
\hline & Total & $10.70 \pm 6.59$ & $10.43 \pm 6.68$ & $11.49 \pm 6.32$ & 0.415 \\
\hline
\end{tabular}

HLA-B27 Human leukocyte antigen B27; BASDAI Bath Ankylosing Spondylitis Disease Activity Index; BASFI Bath Ankylosing Spondylitis Functional Index; $B A S M I$ Bath Ankylosing Spondylitis Metrology Index; ASDAS Ankylosing Spondylitis Disease Activity Score; CRP C-reactive protein; ESR Erythrocyte sedimentation rate; HADS Hospital Anxiety and Depression Scale; NSAIDs Non-steroidal anti-inflammatory drugs; COX-2 Cyclooxygenase-2; DMARDs Disease-modifying antirheumatic drugs; SF-36 36-item short form questionnaire

*statistically significant $(p<0.05)$

musculoskeletal disorders like scoliosis deformities [37]. The higher disease activities supported by increased BASDAI score was identified by a reduction in EQ-5D. Similarly, reduced disease activity shown by reduced BASDAI score is matched by an increased EQ-5D score. No change in disease activity was also supported by no change in EQ-5D scores. Despite a small percentage of individuals with a ceiling effect at baseline and followup, the scores are representative of disease status changes. The ceiling effect indicates the highest possible score on the instrument and normally refers to clustering of scores at a certain extreme. This corresponded to the low disease activity scores that are unlikely to experience further improvement in health at follow-up. Conversely, there is no floor effect indicating that the instrument is sensitive to deteriorations in disease status that warrants treatment regimen changes. Hence, the EQ-5D is an appropriate tool for studying patients with SpA.

Due to the lack of clinically improved patients by ASDAS-CRP, we were unable to formulate any useful conclusions. This may be the limitation of its score to detect patient perceived QoL. Although we followed the clearly established cut-off value of ASDAS-CRP to determine improvement or worsened scores [39], we were unable to identify any individuals with improved ASDA S-CRP despite improved patients categorized by BASDAI. Despite ASDAS-CRP being a more objective assessment of SpA disease activity, it may not reflect the patient's perceived health as well. The components of BASDAI describes more subjective self-perceived components of pain, discomfort, and other disease 


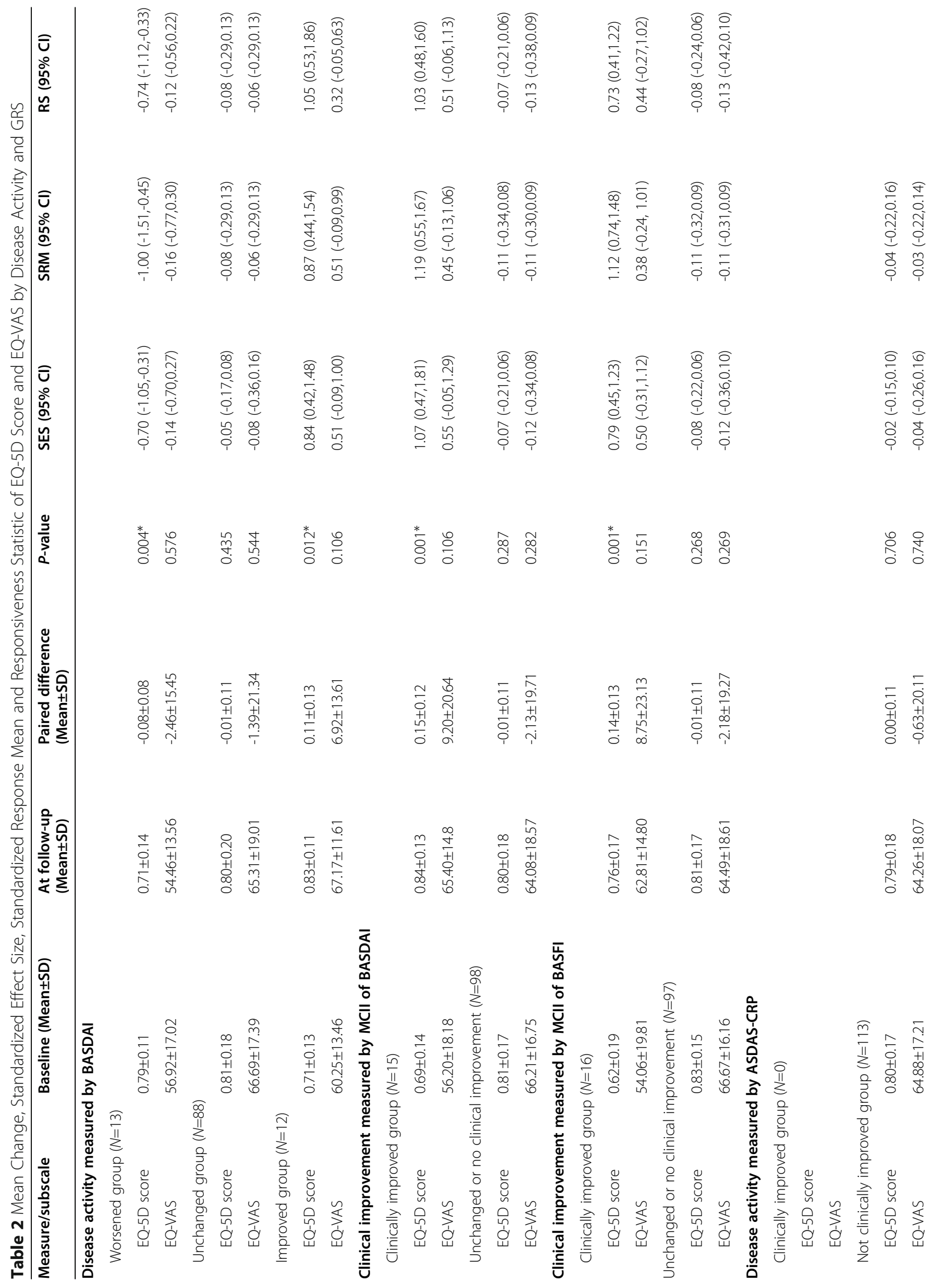




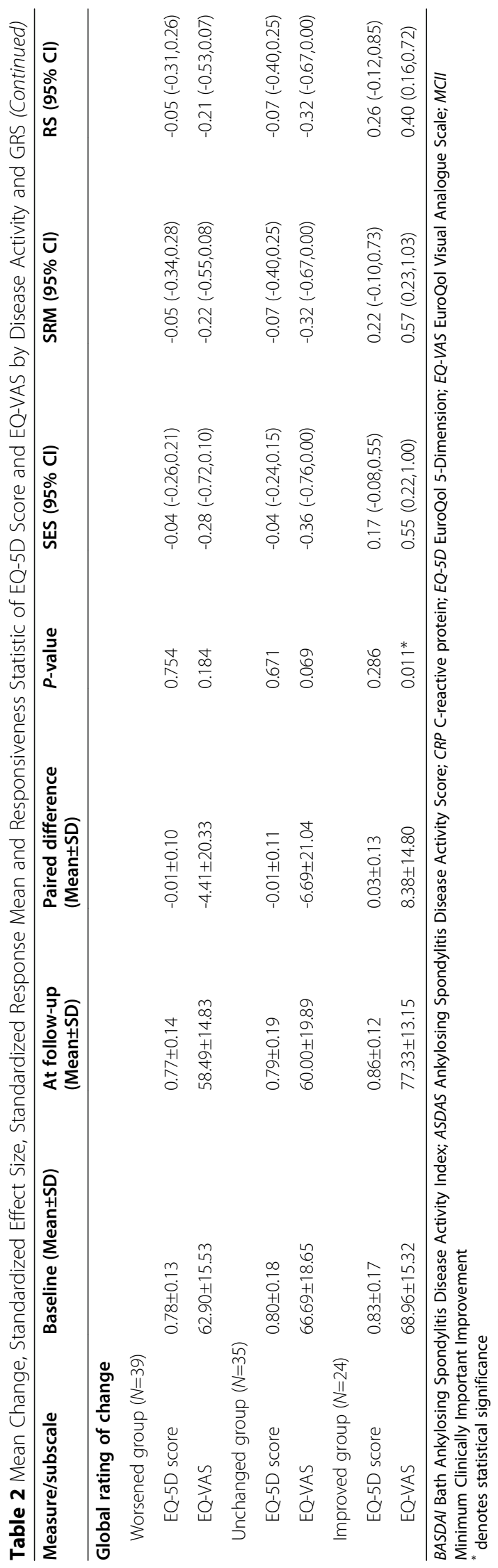




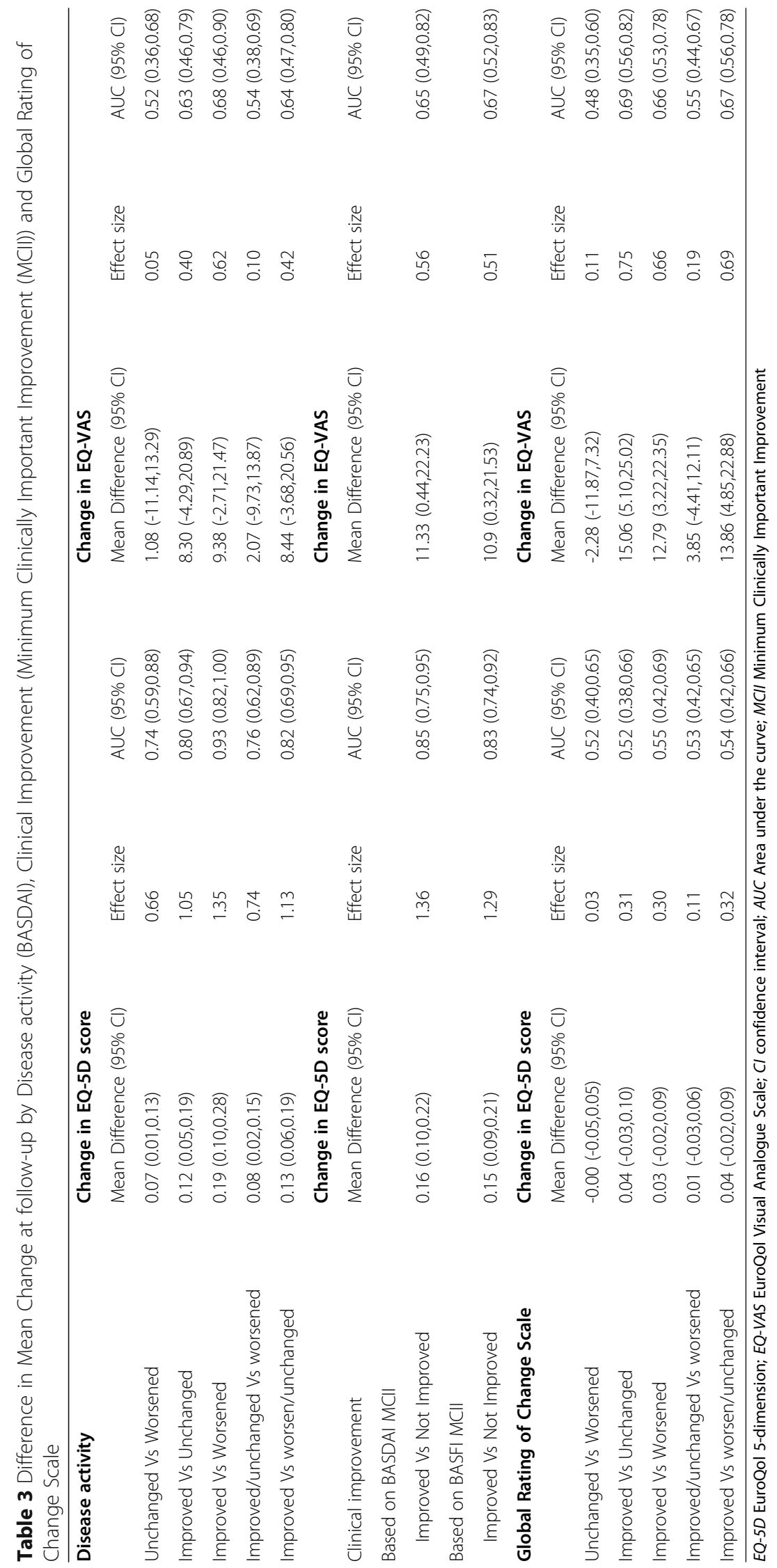


Table 4 Descriptive statistics of EQ-5D-5L utility score and EQ-VAS at baseline and follow-up

\begin{tabular}{|c|c|c|c|c|c|c|}
\hline & Mean & Standard deviation & Observed range & Theoretical range & Floor (\%) & Ceiling (\%) \\
\hline \multicolumn{7}{|l|}{ EQ-5D-5L } \\
\hline Baseline & 0.798 & 0.170 & 0.280 to 1.000 & -0.391 to 1.000 & 0.0 & 6.2 \\
\hline Baseline $^{a}$ & 0.798 & 0.162 & 0.310 to 1.000 & -0.391 to 1.000 & 0.0 & 5.1 \\
\hline Follow-up & 0.794 & 0.185 & -0.110 to 1.000 & -0.391 to 1.000 & 0.0 & 13.3 \\
\hline Mean change & -0.004 & 0.114 & -0.390 to 0.410 & & & \\
\hline \multicolumn{7}{|l|}{ EQ-VAS } \\
\hline Baseline & 64.88 & 17.21 & 10 to 97 & 0 to 100 & 0.0 & 0.0 \\
\hline Baseline $^{a}$ & 65.73 & 16.68 & 15 to 97 & 0 to 100 & 0.0 & 0.0 \\
\hline Follow-up & 64.26 & 18.07 & 5 to 95 & 0 to 100 & 0.0 & 0.0 \\
\hline Mean change & -0.63 & 20.11 & -60 to 50 & & & \\
\hline
\end{tabular}

${ }^{a}$ Baseline descriptive statistics of respondents who have completed both baseline and follow-up

EQ-5D-5L EuroQol 5-dimension 5-level; EQ-VAS EuroQol visual analogue scale

manifestations. Hence, it is expected for BASDAI and EQ-5D to match better since they are both patient perceived HRQoL scores.

It is also interesting to see the GRC scale as an unsatisfactory anchor for EQ-5D changes. This is not an unusual finding. Some HRQoL measures may be more responsive to a clinical anchor rather than GRC [41]. Moreover, the GRC may be affected by many other factors whereas BASDAI is more targeted to the various facets of the disease. Various external factors such as the rapport with the doctor and mental status of the patient may influence the reporting of GRC. Comparatively,

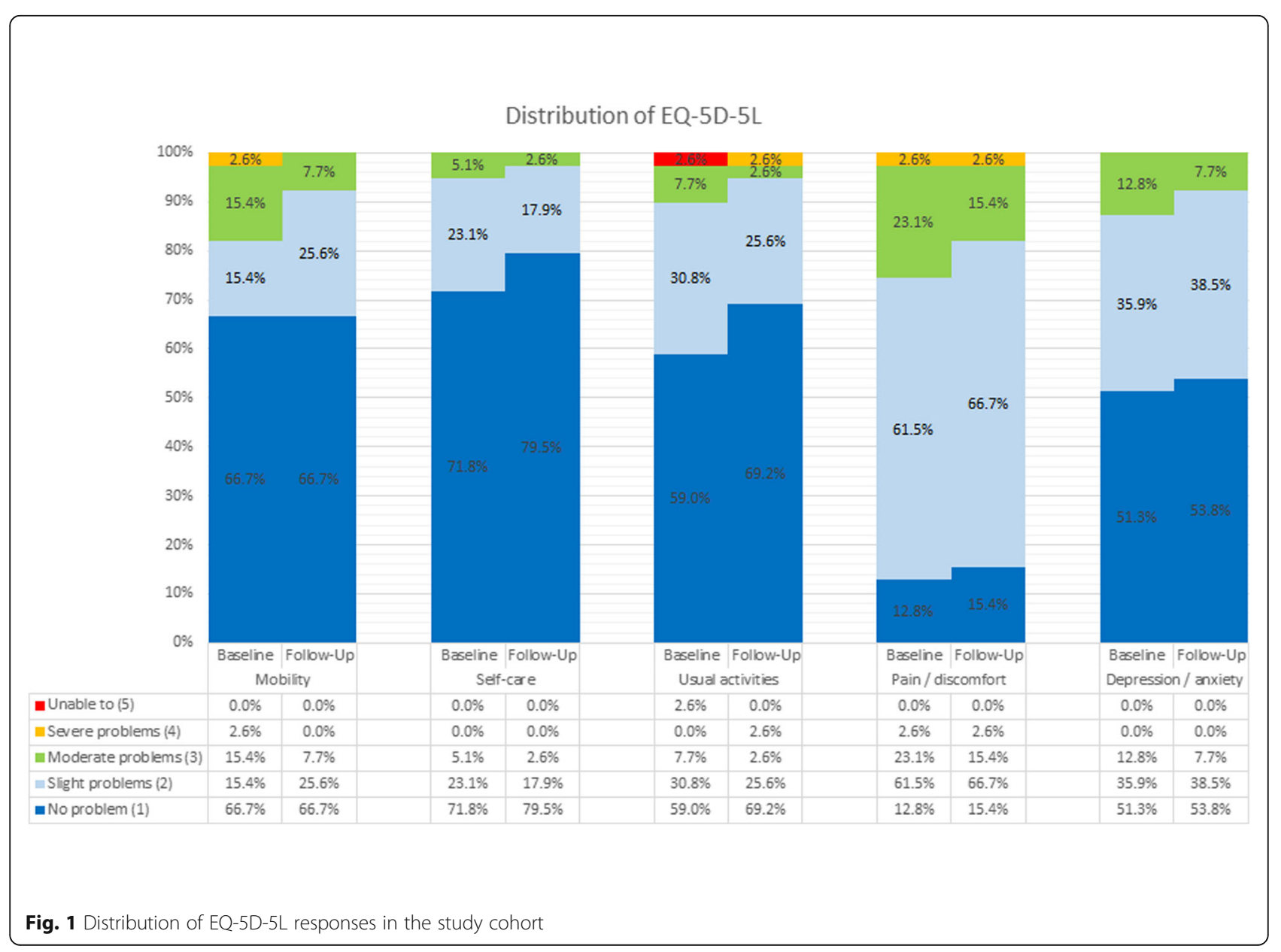




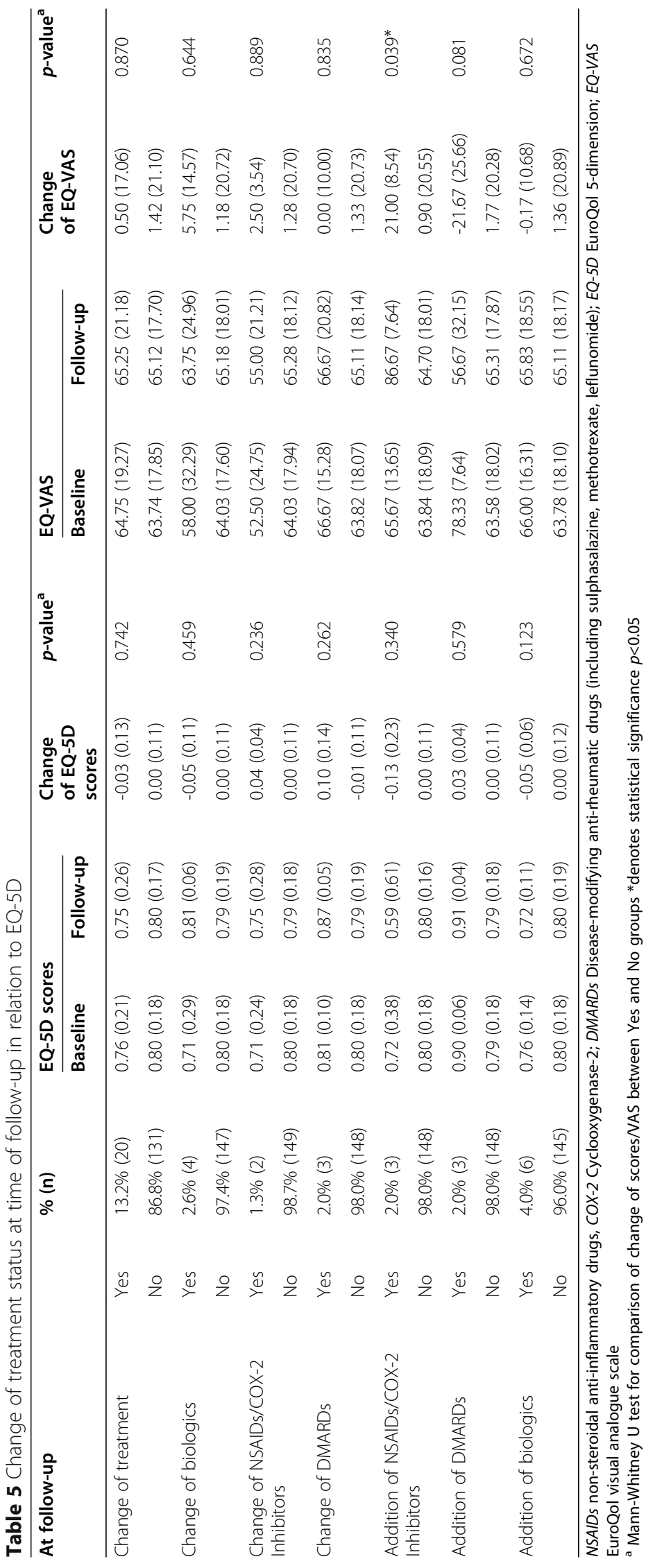


BASDAI is more appropriate for the disease status and it appears that the EQ-5D is able to capture changes in disease status as well.

We also found a significant correlation between EQ5D and HADS. HADS is a tool commonly used by psychiatrists for assessing risks of depression and anxiety. Various studies have demonstrated a prevalence of depression ranging from 11 to $31 \%$ in patients with SpA $[28,42,43]$. By correlating EQ-5D with the HADS scores, we can associate a worse HRQoL in the presence of anxiety and depression. The EQ-5D score can also help identify patients with a higher risk of developing depression and anxiety. We found that the addition of NSAIDs or cox-2 inhibitors correlate with an improvement in EQ-VAS but it did not correlate with the change in EQ-5D scores. This suggests that pain reduction is not the sole determinant of HRQoL for patients with SpA.

The main limitation of this study is an incomplete follow-up of $25 \%$. Nevertheless, the proportion of disease activity categories and patient profiles remain similar. There is also sample heterogeneity with variable presentations of axial or peripheral involvement. Nevertheless, we did have a reasonable effect size generated from the EQ-5D results. It is also important to note that the disease-specific Assessment of SpondyloArthritis international Society (ASAS) health index [44] was not used in this study. This is an instrument that should be compared with EQ-5D in future study.

\section{Conclusion}

The EQ-5D-5L demonstrates satisfactory responsiveness properties for assessment of changes in health status in patients with SpA. It appears to represent the patient reported HRQoL better than more objective assessments. Future study should assess the versatility of the utility score to compare different treatment regimens and its cost-utility with other chronic diseases.

\footnotetext{
Abbreviations

AS: Ankylosing spondylitis; ASDAS: Ankylosing spondylitis disease activity score; AUC: Area under the curve; BASDAl: Bath ankylosing spondylitis disease activity Index; BASFI: Bath ankylosing spondylitis functional index; BASGl: Bath ankylosing spondylitis global index; BASMl: Bath ankylosing spondylitis metrology index; Cox-2: Cyclooxygenase-2; CRP: C-reactive protein; DFI: Dougados functional index; DMARDs: Disease modifying antirheumatic drugs; EQ-5D: EuroQoL 5-dimension; ESR: Erythrocyte sedimentation rate; GRC: Global rating of change; HADS: Hospital anxiety and depression scale; HRQoL: Health-related quality of life; IBD: Inflammatory bowel disease; LDQ: Leeds disability questionnaire; NSAIDs: Non-steroidal anti-inflammatory drugs; PSA: Psoriatic arthritis; QALYs: Quality-adjusted lifeyears; QoL: Quality of life; SD: Standard deviation; SES: Standardized effect size; SF-36: 36-Item short-form; SpA: Spondyloarthritis; SRM: Standardized response mean; VAS: Visual analogue scale; WD: Work disability
}

\section{Authors' contributions}

HHLT was involved in study design, data collection, analysis, interpretation of data and writing and revision of manuscript. CKHW was involved in data analysis and interpretation of data. PWHC was involved in data analysis and interpretation of data, and revision of the manuscript. CSL was involved in data collection and writing of manuscript. HYC was involved in study design, data collection, and writing of manuscript. JPYC was involved in study design, data collection, analysis, interpretation of data, writing and revision of manuscript, and final decision of submission. All authors read and approved the final manuscript.

\section{Funding}

This study was supported by the General Research Fund (GRF) of the Research Grants Council (RGC) \#17156416.

\section{Availability of data and materials}

The datasets used and/or analyzed during the current study are available from the corresponding author on reasonable request. They are not publicly available as they are currently part of a prospective cohort that will be used for future analyses.

\section{Declarations}

Ethics approval and consent to participate

Ethics approval was obtained from the institutional review board of the University of Hong Kong/Hospital Authority Hong Kong West Cluster (UW 17-201). All subjects had informed consent for participation obtained.

\section{Consent for publication}

Written informed consent was obtained from all patients. A copy of the written consent is available for review by the Editor of this journal.

\section{Competing interests}

There are no financial or non-financial competing interests. JPYC is a senior board member of BMC Musculoskeletal Disorders.

\section{Author details}

${ }^{1}$ Department of Medicine, The University of Hong Kong, Hong Kong SAR, China. ${ }^{2}$ Department of Family Medicine and Primary Care, The University of Hong Kong, Hong Kong SAR, China. ${ }^{3}$ Department of Orthopaedics and Traumatology, The University of Hong Kong, Professorial Block, 5th Floor, 102 Pokfulam Road, Pokfulam, Hong Kong SAR, China.

Received: 27 November 2020 Accepted: 30 April 2021

Published online: 14 May 2021

\section{References}

1. Boonen A, van der Heijde D, Landewe R, Spoorenberg A, Schouten $H$, Rutten-van Molken $\mathrm{M}$, et al. Work status and productivity costs due to ankylosing spondylitis: comparison of three European countries. Ann Rheum Dis. 2002;61(5):429-37.

2. Boonen A. Socioeconomic consequences of ankylosing spondylitis. Clin Exp Rheumatol. 2002;20(6 Suppl 28):S23-6.

3. Boonen $A$, de Vet $H$, van der Heijde $D$, van der Linden S. Work status and its determinants among patients with ankylosing spondylitis. A systematic literature review. J Rheumatol. 2001;28(5):1056-62.

4. Boonen A, Chorus A, Miedema H, van der Heijde D, Landewe R, Schouten $\mathrm{H}$, et al. Withdrawal from labour force due to work disability in patients with ankylosing spondylitis. Ann Rheum Dis. 2001;60(11):1033-9.

5. Taser B, Ayhan FF, Borman P. The importance of quality of life for work outcomes in patients with ankylosing spondylitis - a cross-sectional study. Acta Reumatol Port. 2017;42(4):300-9.

6. Alkan BM, Fidan F, Erten S, Aksekili H, Alemdar A, Eroglu E, et al. Fatigue and correlation with disease-specific variables, spinal mobility measures, and health-related quality of life in ankylosing spondylitis. Mod Rheumatol. 2013; 23(6):1101-7.

7. O'Dwyer T, O'Shea F, Wilson F. Decreased health-related physical fitness in adults with ankylosing spondylitis: a cross-sectional controlled study. Physiotherapy. 2016;102(2):202-9. 
8. O'Dwyer T, O'Shea F, Wilson F. Decreased physical activity and cardiorespiratory fitness in adults with ankylosing spondylitis: a crosssectional controlled study. Rheumatol Int. 2015;35(11):1863-72.

9. Shen B, Zhang A, Liu J, Da Z, Xu X, Liu H, et al. Body image disturbance and quality of life in Chinese patients with ankylosing spondylitis. Psychol Psychother. 2014;87(3):324-37.

10. EuroQol G. EuroQol--a new facility for the measurement of health-related quality of life. Health Policy. 1990;16(3):199-208.

11. Luo N, Li M, Liu GG, Lloyd A, de Charro F, Herdman M. Developing the Chinese version of the new 5-level EQ-5D descriptive system: the response scaling approach. Qual Life Res. 2013;22(4):885-90.

12. Tsang HHL, Cheung JPY, Wong CKH, Cheung PWH, Lau CS, Chung HY. Psychometric validation of the EuroQoL 5-dimension (EQ-5D) questionnaire in patients with spondyloarthritis. Arthritis Res Ther. 2019;21(1):41.

13. Rudwaleit M, Landewe R, van der Heijde D, Listing J, Brandt J, Braun J, et al. The development of assessment of SpondyloArthritis international Society classification criteria for axial spondyloarthritis (part I): classification of paper patients by expert opinion including uncertainty appraisal. Ann Rheum Dis. 2009;68(6):770-6.

14. Rudwaleit M, van der Heijde D, Landewe R, Akkoc N, Brandt J, Chou CT, et al. The assessment of SpondyloArthritis International Society classification criteria for peripheral spondyloarthritis and for spondyloarthritis in general. Ann Rheum Dis. 2011;70(1):25-31.

15. Rudwaleit M, van der Heijde D, Landewe R, Listing J, Akkoc N, Brandt J, et al. The development of Assessment of SpondyloArthritis international Society classification criteria for axial spondyloarthritis (part II): validation and final selection. Ann Rheum Dis. 2009;68(6):777-83.

16. Terwee CB, Mokkink LB, Knol DL, Ostelo RW, Bouter LM, de Vet HC. Rating the methodological quality in systematic reviews of studies on measurement properties: a scoring system for the COSMIN checklist. Qual Life Res. 2012;21 (4):651-7.

17. van der Linden S, Valkenburg HA, Cats A. Evaluation of diagnostic criteria for ankylosing spondylitis. A proposal for modification of the New York criteria. Arthritis Rheum. 1984;27(4):361-8.

18. Garrett S, Jenkinson T, Kennedy LG, Whitelock H, Gaisford P, Calin A. A new approach to defining disease status in ankylosing spondylitis: the bath ankylosing spondylitis disease activity index. J Rheumatol. 1994;21 (12):2286-91.

19. Calin A, Garrett S, Whitelock H, Kennedy LG, O'Hea J, Mallorie P, et al. A new approach to defining functional ability in ankylosing spondylitis: the development of the bath ankylosing spondylitis functional index. J Rheumatol. 1994;21(12):2281-5.

20. Jones SD, Porter J, Garrett SL, Kennedy LG, Whitelock H, Calin A. A new scoring system for the Bath Ankylosing Spondylitis Metrology Index (BASMI). J Rheumatol. 1995;22(8):1609.

21. Jones SD, Steiner A, Garrett SL, Calin A. The Bath Ankylosing Spondylitis Patient Global Score (BAS-G). Br J Rheumatol. 1996;35(1):66-71.

22. Lukas C, Landewe R, Sieper J, Dougados M, Davis J, Braun J, et al. Development of an ASAS-endorsed disease activity score (ASDAS) in patients with ankylosing spondylitis. Ann Rheum Dis. 2009;68(1):18-24.

23. Turina MC, Ramiro S, Baeten DL, Mease P, Paramarta JE, Song $I H$, et al. A psychometric analysis of outcome measures in peripheral spondyloarthritis. Ann Rheum Dis. 2016;75(7):1302-7.

24. McHorney CA, Ware JE, Jr., Lu JF, Sherbourne CD. The MOS 36-ltem shortform health survey (SF-36): III. Tests of data quality, scaling assumptions, and reliability across diverse patient groups. Med Care. 1994:32(1):40-66.

25. McHorney CA, Ware JE, Jr., Raczek AE. The MOS 36-Item short-form health survey (SF-36): II. Psychometric and clinical tests of validity in measuring physical and mental health constructs. Med Care. 1993;31(3):247-263.

26. Ware JE Jr, Sherbourne CD. The MOS 36-item short-form health survey (SF-36). I. Conceptual framework and item selection. Med Care. 1992 30(6):473-83.

27. Zigmond AS, Snaith RP. The hospital anxiety and depression scale. Acta Psychiatr Scand. 1983;67(6):361-70.

28. Chan CYY, Tsang HHL, Lau CS, Chung HY. Prevalence of depressive and anxiety disorders and validation of the hospital anxiety and depression scale as a screening tool in axial spondyloarthritis patients. Int J Rheum Dis. 2017: 20(3):317-25.

29. Lin J, Wong CKH, Cheung PWH, Luo N, Cheung JPY. Feasibility of proxyreported EQ-5D-3L-Y and its agreement in self-reported EQ-5D-3L-Y for patients with adolescent idiopathic scoliosis. Spine (Phila Pa 1976). 2020; 45(13):E799-807.
30. Wong CKH, Cheung PWH, Luo N, Lin J, Cheung JPY. Responsiveness of EQ$5 \mathrm{D}$ youth version 5-level (EQ-5D-5L-Y) and 3-level (EQ-5D-3L-Y) in patients with idiopathic scoliosis. Spine (Phila Pa 1976). 2019;44(21):1507-14.

31. Wong CKH, Cheung PWH, Luo N, Cheung JPY. A head-to-head comparison of five-level (EQ-5D-5L-Y) and three-level EQ-5D-Y questionnaires in paediatric patients. Eur J Health Econ. 2019;20(5):647-56.

32. Wong CKH, Cheung PWH, Samartzis D, Luk KD, Cheung KMC, Lam CLK, et al. Mapping the SRS-22r questionnaire onto the EQ-5D-5L utility score in patients with adolescent idiopathic scoliosis. PLoS One. 2017;12(4):e0175847.

33. Cheung PWH, Wong CKH, Samartzis D, Luk KDK, Lam CLK, Cheung KMC, et al. Psychometric validation of the EuroQoL 5-Dimension 5-Level (EQ-5D$5 \mathrm{~L}$ ) in Chinese patients with adolescent idiopathic scoliosis. Scoliosis Spinal Disord. 2016;11:19.

34. Luo N, Liu G, Li M, Guan H, Jin X, Rand-Hendriksen K. Estimating an EQ-5D5L Value Set for China. Value Health. 2017;20(4):662-9.

35. Cella D, Bullinger M, Scott C, Barofsky I. Clinical significance consensus meeting $\mathrm{G}$. group vs individual approaches to understanding the clinical significance of differences or changes in quality of life. Mayo Clin Proc. 2002;77(4):384-92

36. Kamper SJ, Maher CG, Mackay G. Global rating of change scales: a review of strengths and weaknesses and considerations for design. J Man Manip Ther. 2009:17(3):163-70

37. Cheung PWH, Wong CKH, Lau ST, Cheung JPY. Responsiveness of the EuroQoL 5-dimension (EQ-5D) in adolescent idiopathic scoliosis. Eur Spine J. 2018;27(2):278-85

38. Kviatkovsky MJ, Ramiro S, Landewe R, Dougados M, Tubach F, Bellamy N, et al. The Minimum Clinically Important Improvement and Patientacceptable Symptom State in the BASDAI and BASFI for Patients with Ankylosing Spondylitis. J Rheumatol. 2016;43(9):1680-6.

39. Machado P, Landewe R, Lie E, Kvien TK, Braun J, Baker D, et al. Ankylosing Spondylitis Disease Activity Score (ASDAS): defining cut-off values for disease activity states and improvement scores. Ann Rheum Dis. 2011;70(1): 47-53.

40. Cohen J. Statistical power analysis for behavioral science. 2nd ed. Hilsdale: Lawrence Earlbaum Associates; 1988.

41. Eurich DT, Johnson JA, Reid KJ, Spertus JA. Assessing responsiveness of generic and specific health related quality of life measures in heart failure. Health Qual Life Outcomes. 2006:4:89.

42. Ben Tekaya A, Mahmoud I, Hamdi I, Hechmi S, Saidane O, Tekaya R, et al. Depression and Anxiety in Spondyloarthritis: Prevalence and Relationship with Clinical Parameters and Self-Reported Outcome Measures. Turk Psikiyatri Derg. 2019;30(2):90-8.

43. Zhao S, Thong D, Miller N, Duffield SJ, Hughes DM, Chadwick L, et al. The prevalence of depression in axial spondyloarthritis and its association with disease activity: a systematic review and meta-analysis. Arthritis Res Ther. 2018;20(1):140.

44. Kiltz U, van der Heijde D, Boonen A, Akkoc N, Bautista-Molano W, BurgosVargas $R$, et al. Measurement properties of the ASAS Health Index: results of a global study in patients with axial and peripheral spondyloarthritis. Ann Rheum Dis. 2018:77(9):1311-7.

\section{Publisher's Note}

Springer Nature remains neutral with regard to jurisdictional claims in published maps and institutional affiliations.

Ready to submit your research? Choose BMC and benefit from:

- fast, convenient online submission

- thorough peer review by experienced researchers in your field

- rapid publication on acceptance

- support for research data, including large and complex data types

- gold Open Access which fosters wider collaboration and increased citations

- maximum visibility for your research: over $100 \mathrm{M}$ website views per year

At $\mathrm{BMC}$, research is always in progress.

Learn more biomedcentral.com/submissions 